\title{
Role of Biogas in Climate Change Mitigation and Adaptation
}

\author{
Anjana Sharma ${ }^{*}$, Raju Laudari ${ }^{2}$, Kedar Rijal $^{3}$, Lokendra Adhikari ${ }^{4}$ \\ ${ }^{1}$ Disaster Risk Reduction Programme Officer, Action Against Hunger \\ ${ }^{2}$ General Manager, The Timber Corporation of Nepal \\ ${ }^{3}$ Head of Department, Tribhuvan University, Central Department of Environment \\ ${ }^{4}$ Ministry of Forests and Environment, Department of National Parks and Wildife Conservation, Nepal \\ ${ }^{*}$ Corresponding author:: anu22env@gmail.com
}

\section{Abstract}

The study was carried out to analyze the role of biogas in climate change mitigation and adaptation. The study is based on the perception of 108 households of Muralibhanjyang VDC of Dhading district, Nepal. The study showed that amount of greenhouse gas emission was reduced by 3.82 tons per household per year of carbon dioxide equivalent by reducing $65.10 \%$ of fuel wood consumption per household per year. It was found that biogas has an effective role in climate change mitigation by reducing greenhouse gases emission. On installing 352 biogas plants, the number of trees saved in VDC was estimated to be 4083 per year which helps in mitigation and adaptation too. Adaptive capacity was determined on the basis of five different assets by giving the index value for each indicator ranging from one to four, which indicates low to very high value. The indicators of adaptive capacity for human, natural and social assets were obtained with values 2, 3.2, 3 and 1.2, 2.3, 2.1 for biogas users and non-users respectively. The physical and financial assets were obtained similar for both users and non-users (i.e. 3). There was significant difference between the adaptive capacity of biogas users and non-users where the average adaptive capacity value for biogas users was found to be 3.24 (high) and that of non-users was 2.8 (medium to high). It can be said that biogas plays a significant role in climate change adaptation by increasing adaptive capacity.

Key words: Climate change, biogas, adaptive capacity, mitigation.

\section{Introduction}

Climate change is an emerging issue and a global challenge induced by anthropogenic activities. According to UNFCCC, climate change refers to a change of climate which is directly or indirectly caused by human activities that alter the composition of global atmosphere. Energy sector contributes significantly to climate change. Greenhouse gases (GHGs) mainly CO2, $\mathrm{N} 2 \mathrm{O}$ and $\mathrm{CH} 4$ emitted by the energy sector are the major contributors to climate change (IPCC, 2007). Despite having only 0.4 percent of the total global population and being responsible for only 0.025 percent of total GHG emissions in the world, Nepal is the 4th vulnerable country in terms of the adverse impacts of climate change. Renewable energy development is important for reducing global greenhouse gas emission (Nepal, 2008).

Developing countries like Nepal are more susceptible to adverse impacts of climate change as they have limited capacity to cope with hazards associated with changing climate (Kates, 2000). Utilization of biomass based energy resources through appropriate technology interventions has become very important for environment conservation and sustainable rural development (Thapa, 2006). 
Biogas is a renewable energy source used for cooking, lighting and heating purposes. It is a mixture of gases that is composed mainly of CH4 (40- $70 \%), \mathrm{CO} 2$ (30-60\%) and other gases (1-5\%). The calorific value of biogas is about 16-20 MJm-3 (Kurchania et al., 2010). Biogas is a sustainable source of energy which can be managed and used indefinitely without degrading the environment (REA, 2009). Dependency on natural resources is one of the major factors for people's vulnerability to climate change and biogas reduces the dependency on forest resources.

In Dhading district, 3373 biogas plants had been installed by 2009 (BSP, 2012). Biogas technology provides an excellent opportunity for mitigation of greenhouse gas emission and reducing global warming by substituting firewood for cooking, kerosene for lighting and cooking (Pathak et al., 2009). Alternative Energy Promotion Centre has reported that total 352 biogas plants have been installed in Muralibhanjyang VDC of Dhading district.

IPCC defines climate change adaptation as "the adjustment in natural or human systems in response to actual or expected climatic stimuli or their effects, which moderates harm or exploits beneficial opportunities." Dhading district is ranked to have low adaptation capability to climate change. The study was carried out to assess the contribution of biogas in climate change mitigation and adaptation by estimating the GHG emission reduced by biogas, and analyzing the adaptive capacity of biogas users and non-users.

\section{Materials and Methods}

\section{Data Collection}

The study was descriptive, analytical as well as observational type. Primary data were collected through household survey, focus group discussion, key informant interview and secondary data were collected from related organizations, literatures and reports. Biogas users were selected by simple random sampling technique and non-users were selected by considering a control group on the basis of user's economic status, similar family size, etc. Sample size for users was determined by Arkin and Colton formula,

$$
\mathrm{n}=\frac{(\mathrm{N} \mathrm{Z2} \mathrm{P}(1-\mathrm{P}))}{(\mathrm{Nd} 2+\mathrm{Z} 2 * \mathrm{P}(1-\mathrm{P}))}
$$

Where, $\mathrm{n}=$ Sample size

$Z=$ the value of standard variant (at 95\%

of confidence level), $Z=1.96$

$\mathrm{P}=$ estimated population proportion

(0.05)

$\mathrm{d}=$ standard error

$\mathrm{N}=$ Total number of biogas users (352)

One hundred and eight households were surveyed; 72 were biogas users and 36 were non-users, where control method was used for the sample size of biogas non-users on the basis of user's economic status and family size. Seven people were taken as key informants and 2 focus group discussions were held with users and non-users for the primary data collection. To determine the relationship between the adaptive capacity of biogas users and non-users, the collected data were analyzed by $\mathrm{Z}$ test with the help of Microsoft Excel 2007. Arc-GIS 9.3 was used for study area map. 


\section{Data Analysis}

Collected data were analyzed by using Microsoft Excel 2007 to estimate the reduction of GHG emission by biogas and to calculate the statistical data of forest conservation and fuel wood demand. GHGs emission was calculated from the value fuelwood consumption (GHGs emission reduction $=$ Amount of fuel wood saved $*$ GHGs emission per $\mathrm{kg}$ of fuel wood) using emission factor given by IPCC $1,996(1 \mathrm{~kg}$ fuel wood $=1.83 \mathrm{~kg}$ of CO2 eqv.).

Forest conservation by community forest was calculated by using the secondary data of BSP - Nepal report of 2009. BSP (2012) estimated that a single biogas plant can save 11.6 trees per year. Forest area saved was estimated based on the study of Winrock and Eco-Securities (2004) on impact of biogas on forest, where one hectare forest area $=32.8$ tons of fuel wood.

Adaptive capacity was determined on the basis of different assets like human asset, social asset, natural asset, physical asset and financial asset by giving the index value for each indicator (MoE, 2010). We can set the indicators or proxy indicators like education, resources, institutions, facilities etc. depending on the nature of study area. The value for the indicators ranks from 1 to 4 , indicating low to very high value. Total adaptive capacity was obtained taking average of all five assets base capacity. ZTest was been used to analyze relationship between the adaptive capacity of biogas users and non-users.

\section{Results and Discussion}

\section{Reduction in Fuel Wood Demands}

Based on people's perception, demand of fuel wood before and after the use of biogas was found to be $3,212.36 \mathrm{~kg}$ per household per year and 1,134.36 kg per household per year respectively, which showed that $65.10 \%$ of fuelwood was saved by use of biogas. Similarly the study conducted by Chand et al (2012) showed that $62.30 \%$ of fuel wood saved by biogas. It was estimated that 2,091.36 kg per household per year fuel wood has been saved after the installation of biogas plant.

\section{Estimation of GHG Emission Reduction}

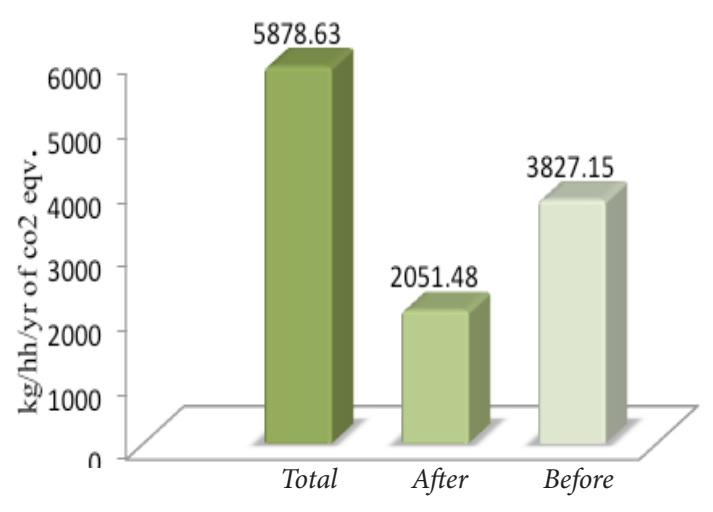

Figure 1: GHGs emission before and after use of biogas 
Reduction in $\mathrm{CO} 2$ emission due to reduction in fuelwood consumption directly helps in climate change mitigation. From the amount of fuel wood saved by using biogas, the amount of GHGs emission reduction was found to be $3,827.15 \mathrm{~kg} / \mathrm{hh} / \mathrm{yr}$ of $\mathrm{CO} 2 \mathrm{eqv}$, i.e., $3.82 \mathrm{tons} / \mathrm{hh} / \mathrm{yr}$ of $\mathrm{CO} 2 \mathrm{eqv}$. which was comparable to the findings of BSP (2012). The estimation of BSP (2012), GHGs emission reduction was 3 tons per plant annually. Reduction in GHGs emission has positive impacts, higher at global level rather than at local level.

\section{Forest Conservation}

After the installation of biogas plant, there was $65.10 \%$ reduction in fuel wood consumption. Still $45 \%$ of fuelwood is being used by the biogas users because of sufficient availability of fuelwood in this VDC. The number of trees saved was estimated to be 4,083 per annum using biogas, using the secondary data of Karki et al (2009). BSP Nepal estimated that a single biogas plant can save 11.6 trees per year. Forest area saved due to the reduction of fuelwood consumption was estimated to be 0.063 ha based on the study of Winrock and Eco-Securities (2004) on impact of biogas on forest, where one hectare forest area $=32.8$ tons of fuel wood. After the forest resources are conserved, water resources will be available, clean air to breathe will be secured and income can be generated by selling the forest products. It may help to increase the adaptive capacity of local people and help in climate change mitigation.

\section{Calculation of Adaptive Capacity}

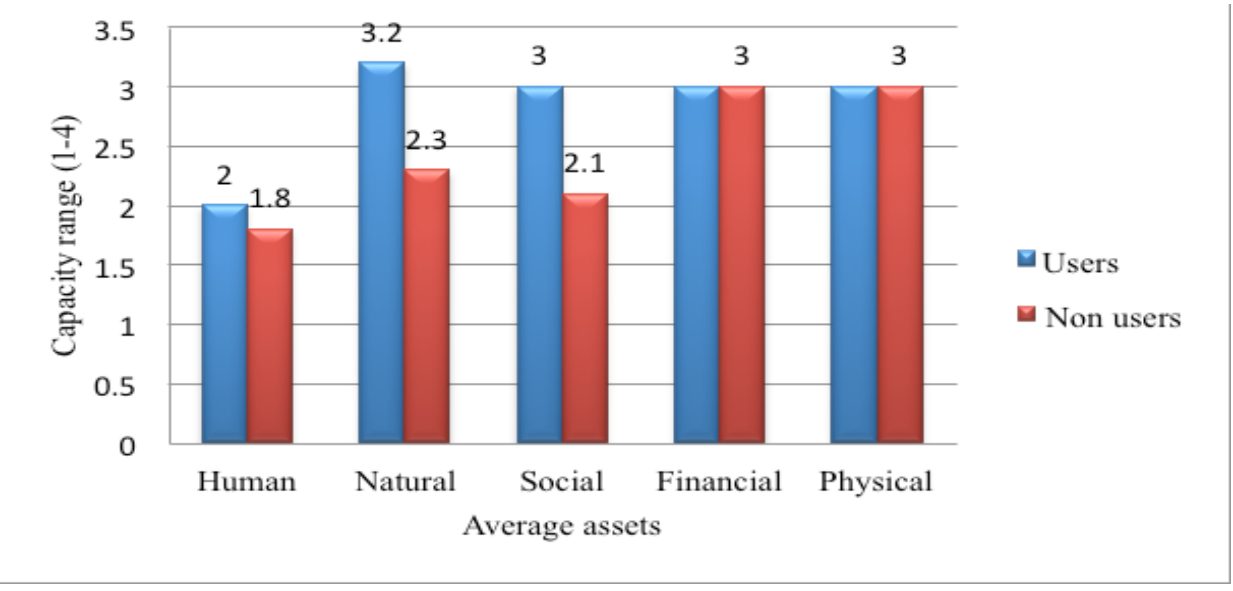

Figure 2: Assets based capacity of users and non-users

The values of indicators (assets) were biogas users and non-users were equal higher for biogas users in average human (user-3, non-user-3) (Fig. 2). The values assets (user-2, non-user-1.8), average of human assets for biogas users were natural assets (user-3.2, non- user-2.3) and higher because of higher education status, average social assets (user-3, non-user-2.1) awareness of climate change, its impacts but the financial and physical assets of both and adaptive needs, skilled labor, number 
of service holder people, etc. The values of natural assets might be higher for the users because of availability of adequate water and other resources and land holding than for the non-users. Natural assets are directly associated with the biogas because of fuelwood. Similarly, social assets for biogas users had more indicator values because of their access to formal and traditional institutions and service providers than for the non-users. The difference between the average values of natural assets for the biogas users and non-users was wider than that in other assets as biogas is directly associated with fuel wood and other natural resources. But the indicator values of financial and physical assets were equal for both the biogas users and non-users. These equalities were because of their similar accessibility in financial institutions, physical infrastructures and similar information and communication facilities they have been using.

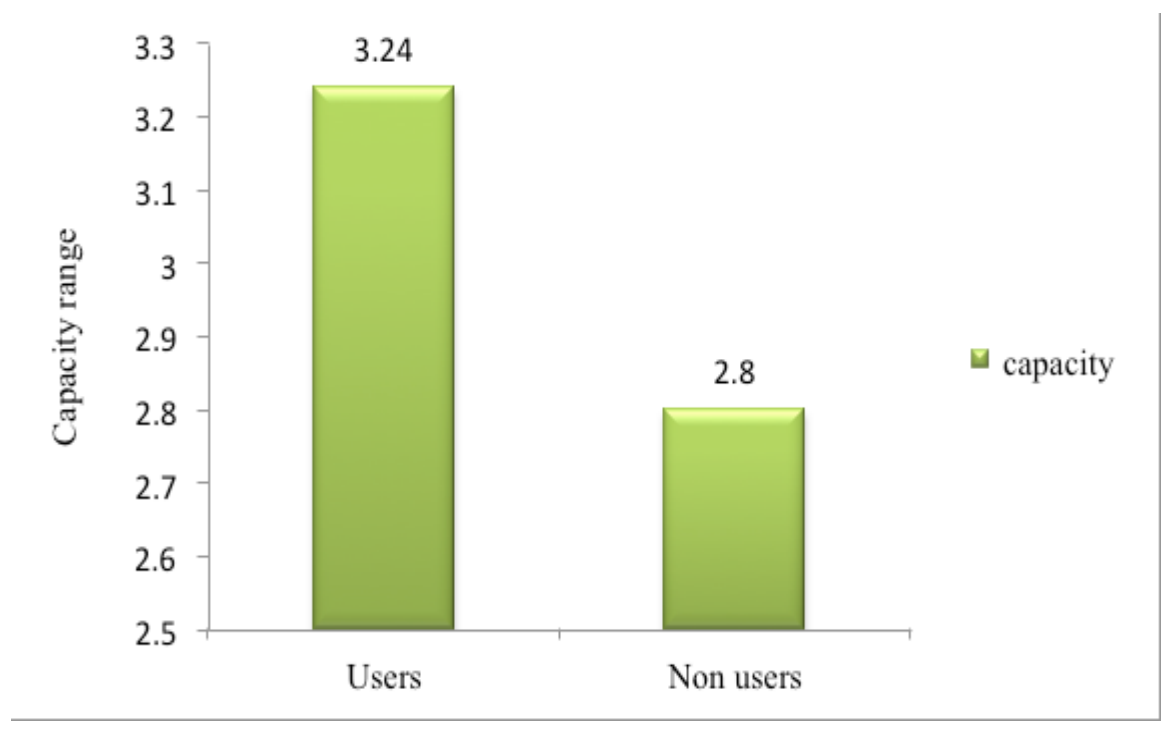

Figure 3: Adaptive capacity of users and non-users

The average adaptive capacity of the biogas user was found to be greater (3.24) than that of the non-users (2.8) (Fig.3). There was significant difference between the adaptive capacity of biogas users and non-users $(\mathrm{Zcal}=3.65)$.

The adaptive capacity of system depends on the targeted assets and their respective indicator values. The higher adaptive capacity of biogas users of the VDC indicated that they could adapt more than the non-users of biogas, i.e. biogas users are more resilient to climate change than the non-users.

Clean energy technologies are considered as potential mitigation measures and are helpful in adaptation. Though the use of biogas shows significant role in adaptation, technology itself is not sufficient to increase the adaptive capacity of the people. It is necessary to integrate technology with income generation activities, information, skill, infrastructure, institution, etc. to obtain the best. 


\section{Coping Mechanism and Adaptation Practices by Local People}

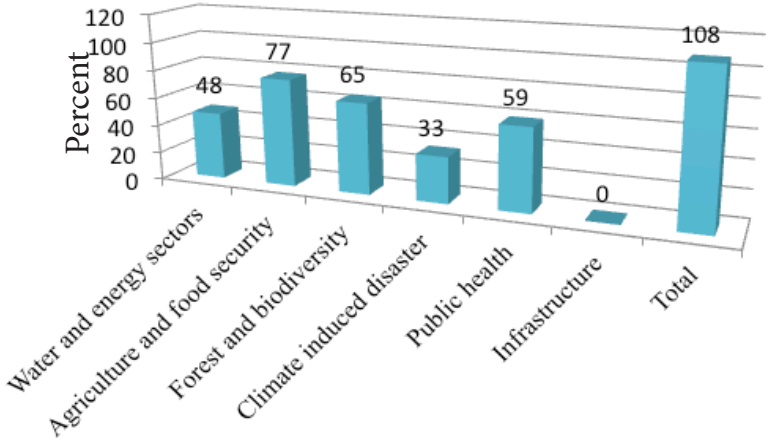

Figure 4: Local adaptation practices in different sectors

Almost all (96\%) of the 108 respondents had felt the consequences of changing climate since long. Uneven distribution and frequency of rainfall, fluctuating temperature characterized by relatively hotter summers and colder winters, alteration in agricultural productions, extinction of traditional sources of drinking water were observed and felt due to climate change in the VDC.

The major adaptation practices used by the people were lifting system for drinking water, forest conservation, use of hybrid seeds, new crop varieties, etc. in agriculture sector (Fig. 4). According to their response, agriculture and food security sector was highly impacted by the changing climate and need to be adapted. Out of 108 respondents, 77 were found to be adapted to agriculture and food security followed by 65 in forest and biodiversity. Still 74.3\% people of VDC depend on agriculture. This might be the reason why maximum households adapt their agriculture and food security sectors to the changing climate for maintaining and increasing the production. People are found to have given emphasis on the preservation of private forest and promotion of community forest as they believe that reforestation will recharge extinct traditional water resources, which is the good indicator of adaptation practices in this VDC.

\section{Conclusion}

Majority of the respondents were farmers followed by service holders followed by tradespeople and labors. The study shows that biogas has effective role in climate change mitigation by reducing the demand of fuelwood, conservation of forest resulting in the reduction of the greenhouse gas emission. Comparing the adaptive capacity by comparing two means, there was significant difference between the adaptive capacity of biogas users and nonusers. The average adaptive capacity value for biogas users was found to be high and that of non-users was medium to high. It can be said that biogas plays a significant role in climate change adaptation by increasing adaptive capacity. Almost all the people are involved in adaptation practices in different sectors where most of them are adapted in agriculture sector. 


\section{Acknowledgements}

I am especially thankful to Alternative Energy Promotion Center (AEPC)/ National Rural and Renewable Energy Program (NRREP) for granting me financial support for this research. I am thankful to

\section{Reference}

BSP, 2012. Biogas Sector Partnership- Nepal, Year book: Interim Phase (Jan 2011-July 2012). http://www. bspnepal.org.np/docs/publication/ year_book_2012.pdf

Chand, M. B., Upadhyay, B. P. and Maskey, R. 2012. Biogas Option for Mitigation and Adaptation of Climate Change. Retech Symposium Compendium, 1: 5-9.

IPCC, 2007. Technical Summary, Contribution of Working Group III to the Fourth Assessment Report of the International Panel on Climate Change. Cambridge University Press, Cambridge, UK.

Karki, A. B., Shrestha, J. N., Baijgain, S. and Sharma, I. 2009. Biogas as Renewable Source of Energy in Nepal: Theory and Development. Biogas Support Program-Nepal, Kathmandu, Nepal.

Kates, R. 2000. Cautionary Tales: Adaptation and the Global Poor. Climate Change, 45: 5-17.

Kurchania, A. K., Panwar, N. L. and Savita, P. D. 2010. Design and Performance evaluation of biogas stove for community cooking application. Internationaljournal of sustainable energy, 29(2): 116-123. the Central Department of Environmental Science for providing me the opportunity to conduct this research work. I appreciate people of Muralibhanjyang VDC for their support and cooperation during my field visit.

MoE, 2010. National Adaptation Programme of Action to Climate Change of Nepal. Ministry of Environment, Singhadurbar, Kathmandu, Nepal.

REA, 2009. Energy and Development. Retrieved on 27 December 2013, http//www.rea net/info/renewable energy.

Thapa, R. 2006. Biomass Stoves in Nepal. National Conference on Renewable Energy Technologies for Rural Development. Kathmandu, Nepal.

Nepal, G. 2008. Policies for Promotion Investment in Energy Sustainability: A Case of Biogas Sector of Nepal. A Paper Prepared for OECD Global Forum on International Investment VII Best practices in promoting investment for development ( $p p$. 27-28). Paris, France: OECD Conference Centre.

Winrock and Eco Securities. 2004. Nepal Biogas Programme. CDM baseline study, Kathmandu, Nepal. 